Research Paper

\title{
In situ biosurfactant production and hydrocarbon removal by Pseudomonas putida CB-100 in bioaugmented and biostimulated oil-contaminated soil
}

\author{
Martínez-Toledo Ángeles ${ }^{1,2}$, Rodríguez-Vázquez Refugio ${ }^{2}$ \\ ${ }^{1}$ Facultad de Ciencias Químicas, Universidad Autónoma de San Luis Potosí, San Luis Potosí, SLP, \\ Mexico. \\ ${ }^{2}$ Departamento de Biotecnología y Bioingeniería, Centro de Investigación y de Estudios Avanzados del \\ IPN, Col. San Pedro Zacatenco, Mexico, D.F., Mexico
}

Submitted: June 29, 2011; Approved: June 05, 2012.

\begin{abstract}
In situ biosurfactant (rhamnolipid) production by Pseudomonas putida CB-100 was achieved during a bioaugmented and biostimulated treatment to remove hydrocarbons from aged contaminated soil from oil well drilling operations. Rhamnolipid production and contaminant removal were determined for several treatments of irradiated and non-irradiated soils: nutrient addition (nitrogen and phosphorus), $P$. putida addition, and addition of both ( $P$. putida and nutrients). The results were compared against a control treatment that consisted of adding only sterilized water to the soils. In treatment with native microorganisms (non-irradiated soils) supplemented with $P$. putida, the removal of total petroleum hydrocarbons (TPH) was $40.6 \%$, the rhamnolipid production was $1.54 \mathrm{mg} / \mathrm{kg}$, and a surface tension of $64 \mathrm{mN} / \mathrm{m}$ was observed as well as a negative correlation $(\mathrm{R}=-0.54 ; \mathrm{p}<0.019)$ between TPH concentration $(\mathrm{mg} / \mathrm{kg})$ and surface tension $(\mathrm{mN} / \mathrm{m})$, When both bacteria and nutrients were involved, TPH levels were lowered to $33.7 \%$, and biosurfactant production and surface tension were $2.03 \mathrm{mg} / \mathrm{kg}$ and $67.3 \mathrm{mN} / \mathrm{m}$, respectively. In irradiated soil treated with P. putida, TPH removal was $24.5 \%$ with rhamnolipid generation of $1.79 \mathrm{mg} / \mathrm{kg}$ and $65.6 \mathrm{mN} / \mathrm{m}$ of surface tension, and a correlation between bacterial growth and biosurfactant production $(\mathrm{R}=-0.64 ; \mathrm{p}<0.009)$ was observed. When the nutrients and P. putida were added, TPH removal was $61.1 \%, 1.85 \mathrm{mg} / \mathrm{kg}$ of biosurfactants were produced, and the surface tension was $55.6 \mathrm{mN} / \mathrm{m}$. In summary, in irradiated and non-irradiated soils, in situ rhamnolipid production by P. putida enhanced TPH decontamination of the soil.
\end{abstract}

Key words: bioremediation, irradiated soil, total petroleum hydrocarbons, rhamnolipids, $P$. putida.

\section{Introduction}

At present, Mexico has severe water, soil, and air pollution problems due to contamination by both organic and inorganic compounds. Total petroleum hydrocarbons (TPH) are considered to be high-priority compounds that should be removed from polluted areas in Mexico (SEMARNAT, 2008). TPH are a mix of pollutants, and in soil, they represent a risk to the health of people and ecosystems (DOF, 2005). Some of these pollutants have low solubility in water and are, therefore, difficult to remove from polluted environments.
For such pollutants, the use of synthetic surface agents has been suggested. These agents enhance the pollutants solubility's (Volkering et al., 1995), leading to their desorption from the soil, thereby making them more accessible to microbial degradation. Certain microorganisms are able to produce extracellular substances (biosurfactants) with similar characteristics to those of synthetic surfactants. Because they have the advantage of being highly biodegradable, these microbial compounds are attractive agents to use in the bioremediation field (Maier and Soberón-Chávez, 2000).

Pseudomonas putida can produce rhamnolipids (Amézcua-Vega et al., 2004) and are able to remove phe-

Send correspondence to R. Rodríguez-Vázquez. Departamento de Biotecnología y Bioingeniería, Centro de Investigación y de Estudios Avanzados del IPN, Av. Instituto Politécnico Nacional \#2508, Col. San Pedro Zacatenco, C. P. 07360, Mexico, D.F., Mexico. E-mail: rrodrig@cinvestav.mx. 
nanthrene in liquid culture medium under certain culture conditions (Martínez-Toledo et al., 2006). The aim of this work was to measure biosurfactant production by $P$. putida in a biostimulated and bioaugmented soil sample and to assess its ability to remove TPH from polluted soils.

\section{Materials and Methods}

Soil sampling and processing: The soil used in this study came from the Petrochemical Complex located in Poza Rica, Veracruz, Mexico, 20³0'6” N and 97'28'33" $\mathrm{W}$. The complex is located in the hydrological region RH27 "Tuxpan Nautla," which includes the river basins of Nautla, Tecolutla, Cazones, and Tuxpan, as well as the Tamihua lagoons. According to the FAO/UNESCO/IRIS, sedimentary rocks are the predominant geological formation of the soil and Vertisols-Gleyic is the dominant type of soil. The area has a warm and wet climate with an annual mean temperature of $24.4{ }^{\circ} \mathrm{C}$, annual precipitation of $1,472.4 \mathrm{~mm}$, and a relative humidity between 76 and $80 \%$ (INEGI, 1997).

Waste from petroleum drilling operations, maintenance, and duct repair has been accumulating in this soil. For this study, the soil was sampled (Figure 1) at a depth of $50 \mathrm{~cm}$ at thirteen points (S.1 - S.13) and down to $2 \mathrm{~m}$ at six points (P.M.1 - P.M.6). The bulk samples were homogenized manually and sieved (2-cm mesh), then kept at $4{ }^{\circ} \mathrm{C}$ in polypropylene containers holding $200 \mathrm{~kg}$. From these containers, $200 \mathrm{~kg}$ was taken and air-dried at room temperature, homogenized manually again, and $500 \mathrm{~g}$ was taken as a representative sample as reported elsewhere (Cline, 1994). Each sample was crushed with a mortar and pestle, passed through a standard sieve of 2-mm mesh size, and kept at $4{ }^{\circ} \mathrm{C}$ in glass amber bottles until its characterization and analysis. Gamma irradiation of the soil was performed at the Gamma Irradiation Department of the National Insti-

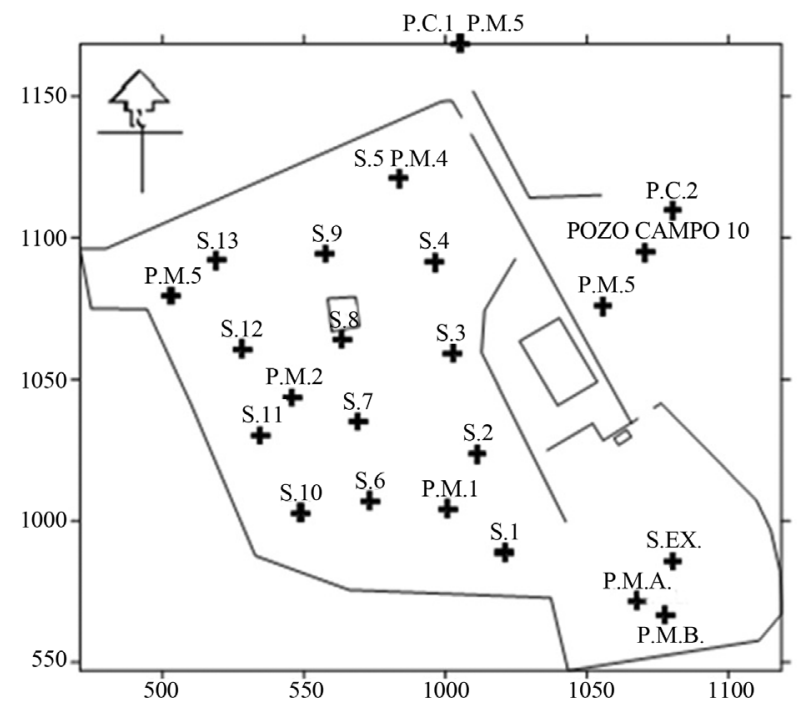

Figure 1 - Soil sampling map. tute of Nuclear Research located in the state of Mexico. The soil was irradiated at $25 \mathrm{kGy}$ in $2-\mathrm{kg}$ polyethylene bags in 5-kg containers (ININ, 2010).

Physical and chemical characteristics of the soil: $\mathrm{Hu}-$ midity was measured by the gravimetric method (Gardner and Klute, 982). The method used for total nitrogen (N) determination (Kjeldahl method) was that reported by Muñoz-Iniestra et al. (2000). Available phosphorus (P) was determined according to Bray and Kurtz in 1945 with modifications (Roldán-Martín et al., 2006). Organic matter was determined through the method of oxidation with chromic and sulfuric acids developed by Walkley and Black in 1947 (Muñoz-Iniestra et al., 2000). The $\mathrm{pH}$ was determined in a $1: 10(\mathrm{w} / \mathrm{v})$ suspension of the soil in distilled water and measured with a Jenway Mod. 3020 potentiometer using epoxy electrodes (Muñoz-Iniestra et al., 2000).

After soil characterization, nutrients were balanced based on the biostimulation experiment. The nutrient sources were $\mathrm{NH}_{4} \mathrm{Cl}(20 \mathrm{mg} / \mathrm{g})$ and $\mathrm{NaNO}_{3}(320 \mathrm{mg} / \mathrm{g})$ for $\mathrm{N}$ and $\mathrm{KH}_{2} \mathrm{PO}_{4}(3.62 \mathrm{mg} / \mathrm{g})$ and $\mathrm{K}_{2} \mathrm{HPO}_{4}(46.66 \mathrm{mg} / \mathrm{g})$ for $\mathrm{P}$, and these were added to obtain a carbon:nitrogen:phosphorus (C:N:P) ratio of 100:10:1 in the soil (Cookson, 1995). Water content was adjusted with sterilized water to $35 \%$.

Inoculum preparation: Preparation for the bioaugmented treatment consisted of inoculation of $P$. putida CB-100 into a culture medium (Martínez-Toledo and Rodríguez-Vázquez, 2010) containing (g/L): glucose (13.6), yeast extract (0.01), $\mathrm{NH}_{4} \mathrm{Cl}(0.5), \mathrm{Fe}_{2} \mathrm{SO}_{4} 7 \mathrm{H}_{2} \mathrm{O}$ (0.0005), $\mathrm{KH}_{2} \mathrm{PO}_{4}(0.2), \mathrm{K}_{2} \mathrm{HPO}_{4}(2), \mathrm{MgSO}_{4} 7 \mathrm{H}_{2} \mathrm{O}$ (1), $\mathrm{NaNO}_{3}(5)$, $\mathrm{FeCl}_{3} 6 \mathrm{H}_{2} \mathrm{O}$ (0.0049), $\mathrm{KCl}(1.1), \mathrm{NaCl}(1.1), \mathrm{CaCl}_{2} 2 \mathrm{H}_{2} \mathrm{O}$ (0.05), $\mathrm{ZnSO}_{4} 7 \mathrm{H}_{2} \mathrm{O}(0.006), \mathrm{MnSO}_{4} \mathrm{H}_{2} \mathrm{O}(0.006), \mathrm{CoCl}_{2}$ $6 \mathrm{H}_{2} \mathrm{O}(0.0006)$, and $\mathrm{CuSO}_{4} 5 \mathrm{H}_{2} \mathrm{O}(0.0006)$. The $\mathrm{pH}$ was adjusted to 7 and incubation continued for $5 \mathrm{~d}$ at $150 \mathrm{rpm}$ and $37^{\circ} \mathrm{C}$. After this time, colony-forming units (cfu) were measured to ensure that the number of $P$. putida colonies was suitable for inoculation (at $10^{9} \mathrm{cfu} / \mathrm{mL}$ ) of the experimental samples. Analyses of N, P, and glucose levels in the inoculum were also performed.

Microcosm units: The microcosm units consisted of sterile serological bottles containing $20 \mathrm{~g}$ of soil (irradiated or non-irradiated) with three replicates of each one of the treatments that are mentioned in the followed paragraph. They were incubated at $37{ }^{\circ} \mathrm{C}$. Destructive analyses were performed after $0,2,4,6,8$, and $10 \mathrm{~d}$ of incubation. Aeration of the microcosm units was performed every $72 \mathrm{~h}$ under sterile conditions by shaking with a vortex for $1 \mathrm{~min}$ and leaving the lid open under sterile conditions for about $5 \mathrm{~min}$.

The following microcosm units were established: 1) soil + sterilized water $=$ control treatment; 2$)$ soil + nutrients $=$ biostimulated treatment $($ Biost T); 3$)$ soil $+P$. putida $=$ bioaugmented treatment $($ BioauT $) ; 4)$ soil + P. putida + nutrients $=$ bioaugmented-biostimulated treatment (BioauT-BiostT).

Colony counts: Heterotrophic microbial growth was monitored (bacteria and fungi). Soil microorganisms were 
enumerated by plate counting methods (Clark, 1982) replicated three times. For bacterial quantification, tryptic soy agar (TSA) was used as a medium and incubation took place at $30{ }^{\circ} \mathrm{C}$ for $48 \mathrm{~h}$. For fungal quantification, Bengal Rose agar plus $0.01 \%$ chloramphenicol was used and the plates were incubated for $7 \mathrm{~d}$ at $28{ }^{\circ} \mathrm{C}$ in a General Signal incubator. The microorganisms were reported as cfu per gram of dry soil.

Extraction of TPH: Extraction was achieved following the modified shaking extraction method of Schwab et al. (1999). Further, $1 \mathrm{~g}$ of the dry soil with $2 \mathrm{~g}$ of $\mathrm{Na}_{2} \mathrm{SO}_{4}$ and $5 \mathrm{~mL}$ of $\mathrm{CH}_{2} \mathrm{Cl}_{2}$ were placed in a conical centrifuge tube, vortexed for $1 \mathrm{~min}$, and then centrifuged at $6,500 \mathrm{rpm}$ for $20 \mathrm{~min}$, and the supernatant was retained. This procedure was repeated three times starting from the addition of $5 \mathrm{~mL}$ of $\mathrm{CH}_{2} \mathrm{Cl}_{2}$. The organic extracts were combined and concentrated to dryness in a rotary evaporator (740 mbar and $40{ }^{\circ} \mathrm{C}$ ); the residue was dissolved in $\mathrm{C}_{2} \mathrm{Cl}_{4}$ and filtered through a glass microfiber filter (Whatman GF/F). The efficiency of this shaking extraction method was previously evaluated and compared with Soxhlet extraction (ArceOrtega et al., 2004; Banks et al., 2000).

Analysis of TPH by infrared spectrophotometry: The modified EPA 8440 (http://www.epa.gov/epaoswer/ hazwaste/test/main.htlm) was used for TPH quantification. A standard curve was generated using the EPA standard reference oil containing a mixture of isooctane, chlorobenzene, and hexadecane with ethylene tetrachloride added to $100 \mathrm{~mL}$. The curve was constructed with five points from 0 to $800 \mathrm{mg} / \mathrm{L}$. Readings were made in an infrared spectrometer (Nicolet Mod. Nexus 470); adsorption was measured at $2,930 \mathrm{~cm}^{-1}$ using a $10-\mathrm{mm}$ Spectra-Tech Inc. IR Quartz TPH cell; data acquisition was performed with the EZ Omnic ESP 5.1 program.

Biosurfactant extraction from soils: The biosurfactants were extracted with an electrolyte solution composed of $10 \mathrm{mM} \mathrm{KNO}_{3}, 10 \mathrm{mM}$ Tris- $\mathrm{HCl}$, and $3 \mathrm{mM} \mathrm{NaN}_{3}$ (used to prevent microbial contamination) at $\mathrm{pH} 7.0$; a 1:2 $(\mathrm{w} / \mathrm{v})$ soil:solution relationship was used by a modified method (Noordman et al., 1994). Ten 10-mL solution samples were placed in $22 \times 175 \mathrm{~mm}$ Pyrex tubes with Teflon lids and $5 \mathrm{~g}$ of soil (from the microcosm units). The tubes were left for $3 \mathrm{~d}$ under reciprocal shaking at $240 \mathrm{rpm}$ and ambient temperature $\left(25-27^{\circ} \mathrm{C}\right)$. Afterwards, they were left to rest for $2 \mathrm{~d}$ and then filtered through a $0.22-\mu \mathrm{m}$ cellulose filter (Millipore). The liquid was used to measure surface tension and to assess the presence of rhamnolipids.

Surface tension measurements: All glass and polypropylene items used for this and for the rhamnolipid determination were acid-washed $\left(0.1 \mathrm{~N} \mathrm{HNO}_{3}\right)$, rinsed with distilled water, and dried in a stove. Measurements of each biosurfactant extract $(10 \mathrm{~mL})$ were performed in triplicate. Surface tension was used as an indirect measure of biosurfactant production (Fox and Bala, 2000). The method is based on the maximum vertical force that is required to sepa- rate a stirrup or a ring from the surface of the liquid being examined and to draw up the film that has formed. A Kruss Processor Tensiometer K12, equipped with a ring, and a Kruss Polyscience digital temperature controller were used at $25^{\circ} \mathrm{C}$. After each measurement, the ring was cleaned with distilled water and then heated briefly above an ethyl acetate flame.

Biosurfactant assays: One milliliter of the biosurfactant extracted from the soil was used for the rhamnolipid analysis to assess the presence of rhamnose, the 6-deoxihexose method was used as reported-by Rhaman et al. (2000a). The extract was mixed with $4.5 \mathrm{~mL}$ of concentrated $\mathrm{H}_{2} \mathrm{SO}_{4}$, vortexed for $2 \mathrm{~min}$ (these procedures were done in an ice bath in order to control the strongly exothermic reaction), and then warmed to $100{ }^{\circ} \mathrm{C}$ for $10 \mathrm{~min}$ (in a warm water bath). Afterwards, it was cooled to room temperature, $0.1 \mathrm{~mL}$ of freshly prepared of $3 \%$ thioglycolic acid (TGA) was added, and the mixture was shaken again and incubated for $3 \mathrm{~h}$ in darkness at ambient temperature. The absorbance was read immediately thereafter at 400 and $430 \mathrm{~nm}$, and a standard curve of rhamnose that had received the same treatment as the samples was used for comparison. The formula employed to assess rhamnolipid content was that reported elsewhere (Rhaman et al., 2000a).

$\mathrm{CO}_{2}$ evolution: Heterotrophic activity was evaluated by an indirect method using $\mathrm{CO}_{2}$ evolution. Gas samples $(2 \mathrm{~mL})$ from the air spaces of the microcosms were collected with a $5-\mathrm{mL}$ gas-tight syringe. A Gow-Mac 550 gas chromatograph equipped with a thermal conductivity detector and an Alltech CTRI stainless steel column was run under isothermal conditions at $25^{\circ} \mathrm{C}$; the injector was set at $40{ }^{\circ} \mathrm{C}$ and the detector at $100{ }^{\circ} \mathrm{C}$. Helium was used as the carrier gas at a flow rate of $45 \mathrm{~mL} / \mathrm{min}$ (Amézcua-Allieri et al., 2003). Data were processed with an integrative Gow-Mac. $\mathrm{CO}_{2}$ evolution was reported in milligrams of $\mathrm{CO}_{2}$ per gram of dry soil $\left(\mathrm{mg} \mathrm{CO}_{2} / \mathrm{g} \mathrm{dm}\right)$. The experimental period was determined by the instantaneous $\mathrm{CO}_{2}$ production in both irradiated soils and non-irradiated soils.

\section{Statistical analyses}

Analyses of variance (ANOVA), general linear model procedures (GLM), Pearsons correlations, and Tukeys multiple comparison test (all at a 0.05 significance level) were performed using SAS (Statistical Analysis Treatment) for Windows version 9.0.

\section{Results}

\section{Polluted soil characterization}

The results of the soil characterization are presented in Table 1. In petroleum-polluted soil, the main obstacle for bioremediation is the excess carbon content from hydrocarbon contamination, which affects the C:N:P ratio. Nevertheless, the soil $\mathrm{pH}$ and organic matter content were considered sufficient to support the bioremediation process (Cookson, 1995; Riser-Roberts, 1998). 
Table 1 - Soil characterization.

\begin{tabular}{lcc}
\hline Parameter & Value & Method \\
\hline Moisture & $21.15 \%$ & Gravimetric \\
Water-holding capacity & $14.4 \%$ & Gravimetric \\
pH & 7.14 & Potentiometric \\
Total nitrogen & $0.1677 \%$ & Kjeldahl \\
Available phosphorus & $1.823 \mathrm{mg} / \mathrm{kg}$ & Bray-Kurtz \\
Organic matter & $6.30 \%$ & Walkley-Black \\
Total petroleum hydrocarbons & $32,421 \mathrm{mg} / \mathrm{kg}$ & \\
Bacteria & $4.08 \times 10^{6} \mathrm{cfu} / \mathrm{g} \mathrm{dm}$ & Agar method \\
Fungi & $2.40 \times 10^{5} \mathrm{cfu} / \mathrm{g} \mathrm{dm}$ & Agar method \\
Textural composition & Sand $31 \%, \mathrm{silt} 34 \%$, & Bouyoucos \\
& clay $35 \%$. & \\
\hline
\end{tabular}

\section{Gamma irradiation of the soil}

Gamma irradiation of the soil was performed and, by comparison with non-irradiated soil, the changes in the initial flora present and their ability to remove toxins and produce biosurfactants during the experimental period were determined. To investigate whether the initial TPH concentrations were altered by gamma irradiation, extractions were performed on irradiated soil samples $(\mathrm{n}=3)$ and on non-irradiated soil samples $(n=3)$. The statistical analysis (ANOVA) revealed no significant difference $(\mathrm{p}<0.61)$ between the TPH concentrations of the non-irradiated and irradiated soil samples; therefore, the TPH were not affected by gamma irradiation. However, gamma irradiation only destroys and inactivates part of the microbial population of the natural contaminated soil.

\section{$\mathrm{CO}_{2}$ evolution}

The experiments were stopped based on the instantaneous $\mathrm{CO}_{2}$ evolution observed in irradiated soil and nonirradiated soil treatments (Figure 2). In the irradiated soil: a total of $1.61 \mathrm{mg}$ of cumulative $\mathrm{CO}_{2} / \mathrm{g} \mathrm{dm}$ were produced in $10 \mathrm{~d}$ with BioauT and, with BioauT-BiostT, $1.72 \mathrm{mg} / \mathrm{g} \mathrm{dm}$ were produced; these two treatments produced similar values as did the control and BiostT. In the non-irradiated soil: with BioauT-BiostT, $2.95 \mathrm{mg}$ of cumulative $\mathrm{CO}_{2} / \mathrm{g} \mathrm{dm}$ were produced in $10 \mathrm{~d}$ and, with BioauT, $1.87 \mathrm{mg} / \mathrm{g} \mathrm{dm}$ were produced; the control and Biost T presented analogous results. A negative correlation was observed between $\mathrm{P}$ content and cumulative $\mathrm{CO}_{2}$ concentration $(\mathrm{R}=-0.78$, $\mathrm{p}<0.0001)$. However, with BiostT the accumulation of $\mathrm{CO}_{2}$ was less than with control treatments.

\section{Microorganism activity}

\section{Bacterial growth (BacG)}

In the irradiated soil, a quick reactivation of bacteria was observed with slight fluctuations during the experimental period (Figure 3A). In all experimental treatments,
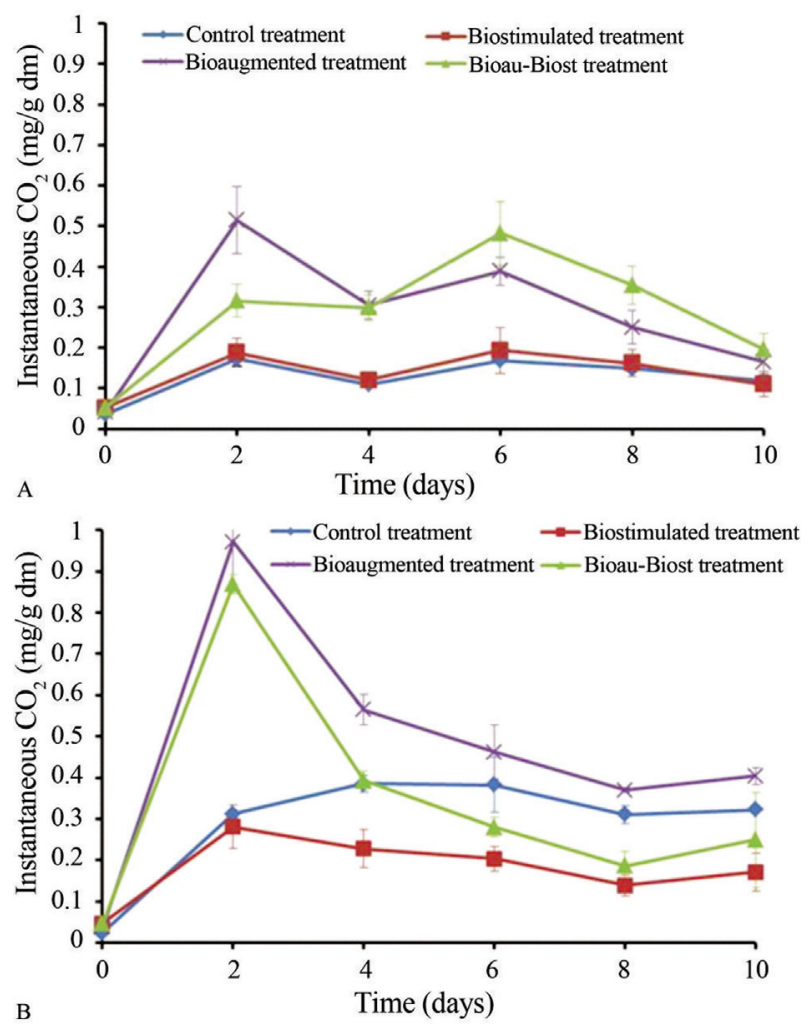

Figure 2 - Instantaneous $\mathrm{CO}_{2}$ production in $\mathrm{A}$ ) irradiated soil and $\mathrm{B}$ ) non-irradiated soil.

maximum cell growth was observed at day 6 (at values of approximately $2.6 \times 10^{9} \mathrm{cfu} / \mathrm{g} \mathrm{dm}$ ); this microbial population could be resistant to gamma irradiation so they were reactivated under appropriate culture conditions. In the non-irradiated soil, the maximum cell growth in all treatments was observed at day 6 (Figure 3B). In the control treatment, bacteria were reactivated at day 4 , and the maximum growth was $2.8 \times 10^{8} \mathrm{cfu} / \mathrm{g} \mathrm{dm}$. With biostimulation, BacG fluctuated over time with a maximum of $2.1 \times 10^{8}$ $\mathrm{cfu} / \mathrm{g} \mathrm{dm}$. In BioauT, the maximum BacG was $5.6 \times 10^{8}$ $\mathrm{cfu} / \mathrm{g} \mathrm{dm}$, after which it declined. Finally, in BioauTBiost T, bacterial numbers remained constant (maximum of $\left.1.4 \times 10^{8} \mathrm{cfu} / \mathrm{g} \mathrm{dm}\right)$.

\section{Fungal growth (FungG)}

In irradiated soil, the reactivation of fungi after gamma irradiation was lower than that of bacteria (Figure 4A). Fungal colony numbers (just the microorganisms that could be resistant to gamma irradiation and were reactivated under appropriate culture conditions) also fluctuated over time. At day 10, a maximum of $4.4 \times 10^{2} \mathrm{cfu} / \mathrm{g} \mathrm{dm}$ were observed under control conditions. With BiostT, faster reactivation was detected than with the control; 1.17 $\mathrm{x} 10^{3} \mathrm{cfu} / \mathrm{g} \mathrm{dm}$ were observed at day 10 . BioauT presented fluctuations in FungG with a maximum of $1.2 \times 10^{3} \mathrm{cfu} / \mathrm{g}$ $\mathrm{dm}$ at day 6. In BioauT-BiostT, growth was slow, but on day 8 rapid growth was observed that continued until day 

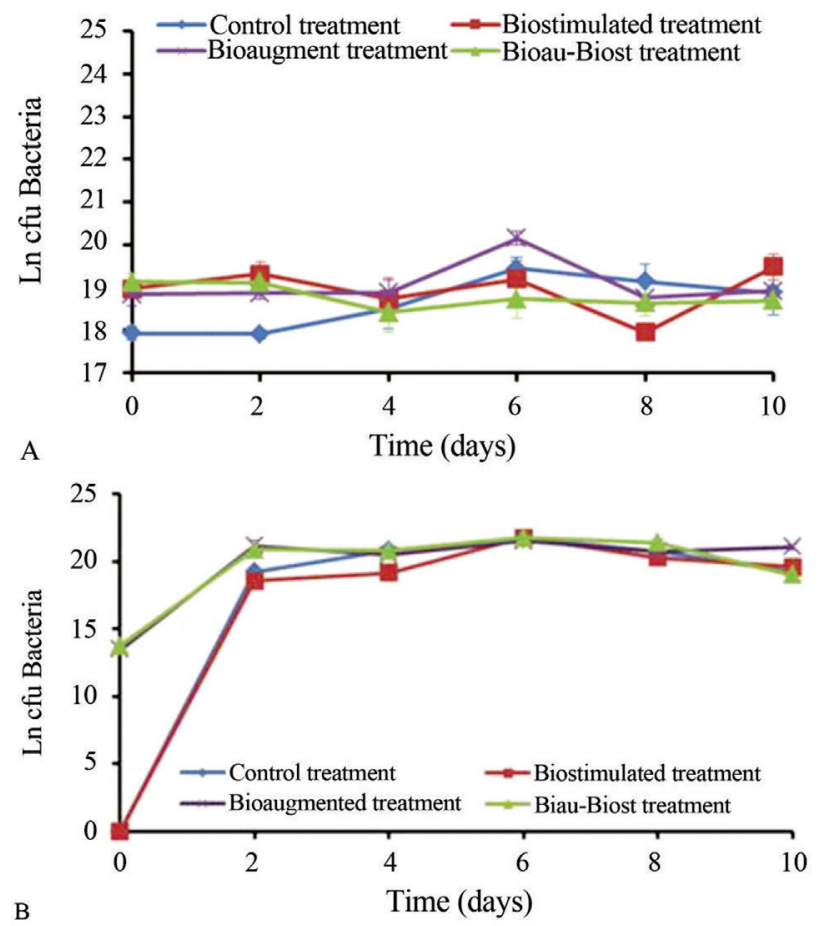

Figure 3 - Bacterial growth in A) irradiated soil and B) non-irradiated soil.

$10\left(1.95 \times 10^{3} \mathrm{cfu} / \mathrm{g} \mathrm{dm}\right)$. In non-irradiated soil, in the control, the colony numbers fluctuated over time, with the maximum count $\left(9.2 \times 10^{5} \mathrm{cfu} / \mathrm{g} \mathrm{dm}\right)$ observed at day 8 (Figure 4B). With BiostT, fungi grew during the first half of the experiment to $5.6 \times 10^{5} \mathrm{cfu} / \mathrm{g} \mathrm{dm}$. With BioauT, better growth was observed with a maximum of $1.0 \times 10^{6} \mathrm{cfu} / \mathrm{g}$ $\mathrm{dm}$ on day 4. In BioauT-BiostT, colony numbers fluctuated at the beginning of the experiment, but the maximum was observed on day $4\left(5.3 \times 10^{5} \mathrm{cfu} / \mathrm{g} \mathrm{dm}\right)$. Humidity measurements remained constant throughout the experimental period in all the experimental units, and this condition supported microbial activity in the soil. The $\mathrm{pH}$ ranged from 7 to 7.5 in all experimental treatments with irradiated soil; these conditions favored BacG. In non-irradiated soil the $\mathrm{pH}$ ranged from 6.9 to 8.0 ; these values sustained the interaction between the bacteria and fungi in the soil to enhance removal of contaminants.

Pearsons correlation analysis revealed that, in BioauT with either non-irradiated or irradiated soil, cumulative $\mathrm{CO}_{2}$ evolution was significantly positively correlated with FungG $(\mathrm{R}=0.64, \mathrm{p}<0.003$ and $\mathrm{R}=0.81, \mathrm{p}<0.007$, respectively). In the irradiated soil, cumulative $\mathrm{CO}_{2}$ evolution was correlated with $\mathrm{BacG}(\mathrm{R}=0.68, \mathrm{p}<0.003)$ in BioauT, and in BioauT-BiostT growth of bacteria and fungi was correlated with $\mathrm{CO}_{2}$ evolution $(\mathrm{R}=0.55, \mathrm{p}<0.048$, $\mathrm{R}=0.78, \mathrm{p}<0.002$, respectively). In the non-irradiated soil, FungG was correlated with cumulative $\mathrm{CO}_{2}$ $(\mathrm{R}=0.649, \mathrm{p}<0.003)$ in BioauT, and in BioauT-BiostT, $\mathrm{BacG}$ was correlated with cumulative $\mathrm{CO}_{2}$ evolution $(\mathrm{R}=-0.55, \mathrm{p}<0.016)$. Therefore, it could be inferred that
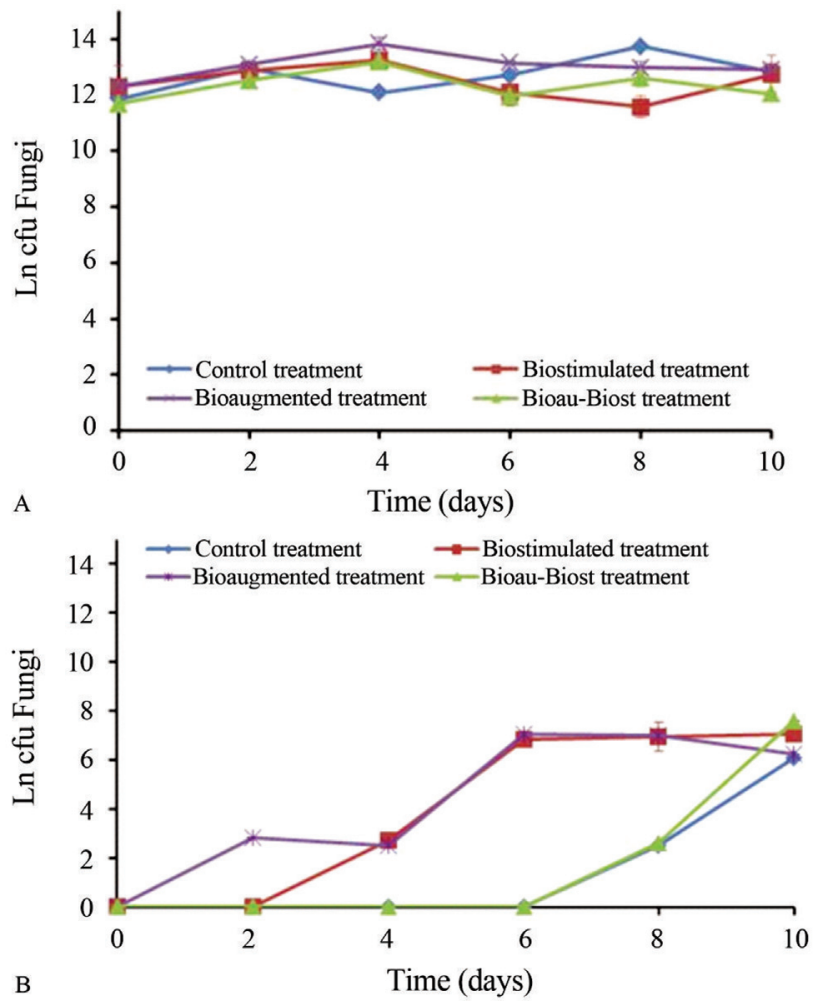

Figure 4 - Fungal growth in A) irradiated soil and B) non-irradiated soil.

$\mathrm{CO}_{2}$ production in the experimental treatments could be attributed to the microbial activity in the soil (both irradiated and non-irradiated), but in the non-irradiated soil FungG played an important role into the microbial population of soil.

\section{Nutrient consumption}

\section{Phosphorus (P)}

Was the most highly consumed nutrient (Table 2). In the irradiated soil: $\mathrm{P}$ concentration $([\mathrm{P}])$ was depleted in both BiostT (80\%) and BioauT-BiostT (76\%) at day 10. In the non-irradiated soil: with BiostT, P was $74 \%$ consumed at day 10 , and in BioauT-BiostT, $\mathrm{P}$ was $53 \%$ consumed at day 10.

\section{Nitrogen $(N)$}

In the control treatment and in BiostT with either irradiated or non-irradiated soil, $\mathrm{N}$ concentration $([\mathrm{N}])$ did not vary significantly during the experimental period (Table 2 ). In the irradiated soil: with BioauT, $35 \%$ of the $\mathrm{N}$ was consumed at day 2, and in BioauT-Biost T, $\mathrm{N}$ was consumed at the same rate $(34 \%)$ on the same day. Pearsons correlation analysis indicated that $[\mathrm{N}]$ was correlated with $\mathrm{BacG}$ and rhamnolipid production in BioauT $(\mathrm{R}=-0.82, \mathrm{p}<0.0001$ and $\mathrm{R}=0.69, \mathrm{p}<0.003$, respectively) and, in combined BioauT-BiostT, $[\mathrm{N}]$ was correlated with the decrease in surface tension $(R=0.55, p<0.037)$. These results show that $\mathrm{N}$ was an important nutrient for $\mathrm{BacG}$ and biosur- 
factant production. In the non-irradiated soil: with BioauT-BiostT, $30 \%$ of the [N] was depleted at day 6 . In this treatment, the statistical analyses indicated that $[\mathrm{N}]$ and $[\mathrm{P}]$ were positively correlated $(\mathrm{R}=0.66, \mathrm{p}<0.002)$, and in BioauT, $[\mathrm{N}]$ was positively correlated with FungG $(\mathrm{R}=0.64, \mathrm{p}<0.003)$ and negatively correlated with $[\mathrm{P}]$ $(\mathrm{R}=-0.64, \mathrm{p}<0.003)$. In this case $\mathrm{N}$ was the preferred nutrient of the fungal population.

\section{TPH removal}

TPH removal was due to the presence of microorganisms (Table 3), and each treatment displayed a different behavior. Pollutant removal was quantified as the difference between the TPH values at the beginning and end of each experiment. ANOVA revealed that the experimental treatments had a significant effect $(p<0.0001)$ on TPH concentration $(\mathrm{mg} / \mathrm{kg})$. Multiple comparison tests revealed four

Table 2 - Nutrient concentrations in the experimental treatments.

\begin{tabular}{|c|c|c|c|c|c|c|c|c|}
\hline \multirow[t]{3}{*}{ Time (days) } & \multicolumn{8}{|c|}{ Phosphorus concentration (mg/kg) } \\
\hline & \multicolumn{2}{|c|}{ Control } & \multicolumn{2}{|c|}{ Biostimulated } & \multicolumn{2}{|c|}{ Bioaugmented } & \multicolumn{2}{|c|}{ Bioau-Biost } \\
\hline & IS & NIS & IS & NIS & IS & NIS & IS & NIS \\
\hline 0 & $1.44 \pm 0.23$ & $1.00 \pm 0.09$ & $30.67 \pm 0.42$ & $24.74 \pm 4.9$ & $2.06 \pm 0.42$ & $1.77 \pm 0.40$ & $27.12 \pm 4.5$ & $17.58 \pm 2.5$ \\
\hline 2 & $1.16 \pm 0.31$ & $0.98 \pm 0.10$ & $29.99 \pm 6.02$ & $13.52 \pm 2.9$ & $1.32 \pm 0.78$ & $1.49 \pm 0.28$ & $15.06 \pm 0.0$ & $9.45 \pm 1.93$ \\
\hline 4 & $1.23 \pm 0.45$ & $1.14 \pm 0.16$ & $21.20 \pm 5.45$ & $10.64 \pm 1.7$ & $0.96 \pm 0.15$ & $1.19 \pm 0.11$ & $22.35 \pm 3.4$ & $9.85 \pm 1.11$ \\
\hline 6 & $1.03 \pm 0.09$ & $1.13 \pm 0.08$ & $11.76 \pm 0.36$ & $7.31 \pm 3.52$ & $2.50 \pm 0.91$ & $1.36 \pm 0.11$ & $15.66 \pm 1.5$ & $5.52 \pm 1.19$ \\
\hline 8 & $1.64 \pm 0.26$ & $1.54 \pm 0.45$ & $11.71 \pm 1.27$ & $8.27 \pm 2.54$ & $1.24 \pm 0.41$ & $1.26 \pm 0.14$ & $8.81 \pm 1.53$ & $7.76 \pm 2.87$ \\
\hline \multirow[t]{2}{*}{10} & $1.24 \pm 0.38$ & $1.06 \pm 0.33$ & $6.05 \pm 1.25$ & $6.39 \pm 1.30$ & $1.06 \pm 0.03$ & $1.20 \pm 0.24$ & $6.38 \pm 3.25$ & $8.30 \pm 3.05$ \\
\hline & \multicolumn{8}{|c|}{ Nitrogen concentration (\%) } \\
\hline 0 & $0.16 \pm 0.01$ & $0.16 \pm 0.01$ & $0.29 \pm 0.06$ & $0.29 \pm 0.01$ & $0.16 \pm 0.01$ & $0.14 \pm 0.01$ & $0.35 \pm 0.01$ & $0.35 \pm 0.01$ \\
\hline 2 & $0.10 \pm 0.00$ & $0.16 \pm 0.01$ & $0.29 \pm 0.01$ & $0.32 \pm 0.02$ & $0.10 \pm 0.01$ & $0.18 \pm 0.03$ & $0.23 \pm 0.00$ & $0.31 \pm 0.01$ \\
\hline 4 & $0.11 \pm 0.01$ & $0.19 \pm 0.02$ & $0.33 \pm 0.02$ & $0.32 \pm 0.02$ & $0.15 \pm 0.04$ & $0.19 \pm 0.01$ & $0.26 \pm 0.03$ & $0.32 \pm 0.02$ \\
\hline 6 & $0.17 \pm 0.01$ & $0.15 \pm 0.01$ & $0.31 \pm 0.05$ & $0.31 \pm 0.01$ & $0.16 \pm 0.00$ & $0.15 \pm 0.00$ & $0.30 \pm 0.03$ & $0.25 \pm 0.02$ \\
\hline 8 & $0.16 \pm 0.01$ & $0.17 \pm 0.02$ & $0.31 \pm 0.00$ & $0.31 \pm 0.01$ & $0.16 \pm 0.00$ & $0.18 \pm 0.01$ & $0.31 \pm 0.03$ & $0.32 \pm 0.01$ \\
\hline 10 & $0.16 \pm 0.01$ & $0.18 \pm 0.02$ & $0.31 \pm 0.01$ & $0.34 \pm 0.04$ & $0.15 \pm 0.01$ & $0.19 \pm 0.00$ & $0.34 \pm 0.04$ & $0.28 \pm 0.00$ \\
\hline
\end{tabular}

I S = Irradiated soil; NIS = Non-irradiated soil; $\pm=$ Standard deviation.

Table 3 - TPH concentrations $(\mathrm{mg} / \mathrm{kg})$ and removal (\%) in the experimental treatments.

\begin{tabular}{lcccc}
\hline \multirow{2}{*}{ Time (days) } & Control & Biostimulated & Bioaugmented & BioauT-BiostT \\
\cline { 3 - 5 } & $33,398 \pm 8,444(0.0 \%)$ & $30,204 \pm 3,355(0.0 \%)$ & $31,75 \pm 5,017(0.0 \%)$ & $35,966 \pm 2,748(0.0 \%)$ \\
2 & $38,459 \pm 2,574(-15.1 \%)$ & $19,507 \pm 5,311(35.0 \%)$ & $13,833 \pm 3,313(56.4 \%)$ & $33,989 \pm 1,230(5.9 \%)$ \\
4 & $35,768 \pm 3,557(-7.0 \%)$ & $18,853 \pm 5,043(37.5 \%)$ & $19,832 \pm 4,153(37.5 \%)$ & $15,607 \pm 3,961(56.6 \%)$ \\
6 & $39,103 \pm 3,906(-17.0 \%)$ & $12,691 \pm 2,135(57.9 \%)$ & $22,300 \pm 5,162(29.7 \%)$ & $14,695 \pm 3,980(59.1 \%)$ \\
8 & $37,187 \pm 1,0037(-11.3 \%)$ & $22,471 \pm 6,081(35.6 \%)$ & $20,679 \pm 4,630(34.9 \%)$ & $8,765 \pm 1,539(75.6 \%)$ \\
10 & $31,470 \pm 3,757(5.8 \%)$ & $21,419 \pm 5,600(29.0 \%)$ & $24,020 \pm 3,557(24.5 \%)$ & $13,986 \pm 1,832(61.1 \%)$ \\
\hline & & Non - irradiated soil & & \\
0 & $33,513 \pm 7,462(0.0 \%)$ & $35,615 \pm 8,198(0.00 \%)$ & $33,975 \pm 8,940(0.0 \%)$ & $35,472 \pm 5,196(0.0 \%)$ \\
2 & $40,846 \pm 7,186(-21.9 \%)$ & $38,312 \pm 6,484(-7.5 \%)$ & $21,815 \pm 5,719(35.8 \%)$ & $21,660 \pm 4,214(38.9 \%)$ \\
4 & $31,908 \pm 3,445(4.8 \%)$ & $26,674 \pm 6,041(25.1 \%)$ & $26,024 \pm 5,671(23.4 \%)$ & $29,824 \pm 4,102(15.9 \%)$ \\
6 & $31,360 \pm 6,213(6.4 \%)$ & $31,688 \pm 5,141(11.0 \%)$ & $22,224 \pm 5,710(34.6 \%)$ & $31,041 \pm 1,648(12.5 \%)$ \\
8 & $31,457 \pm 4,645(6.1 \%)$ & $35,878 \pm 3,488(-0.7 \%)$ & $22,411 \pm 3,811(34.0 \%)$ & $28,300 \pm 7,272(20.2 \%)$ \\
10 & $27,599 \pm 2,246(17.6 \%)$ & $30,808 \pm 7,987(13.5 \%)$ & $20,191 \pm 4,508(40.6 \%)$ & $23,517 \pm 2,361(33.7 \%)$ \\
\hline
\end{tabular}

Note: The negative values represent pollutants desorption and the positive values represent pollutant removal. IS $=$ Irradiated soil; NIS $=$ Non-irradiated soil $\pm=$ Standard deviation. 
groups; only the control treatment was significantly different from the other experimental treatments. In the irradiated soil, pollutant desorption was observed in the control treatment, but the best results were obtained with BioauTBiostT: the initial TPH concentration was $35,966 \mathrm{mg} / \mathrm{kg}$ and the final TPH concentration was $13,986 \mathrm{mg} / \mathrm{kg}(61.1 \%$ removal). The remaining experimental treatments (BioauT and BiostT) produced fluctuations between removal and desorption of pollutants. Negative correlation was observed between TPH removal (\%) and rhamnolipid production $(\mathrm{mg} / \mathrm{kg})(\mathrm{R}=-0.55, \mathrm{p}<0.033)$ in BiostT, but also a correlation between cumulative $\mathrm{CO}_{2}$ evolution and TPH concentration $(\mathrm{mg} / \mathrm{kg})$ was observed in BioauT-BiostT.

In the experimental treatments with non-irradiated soil, ANOVA revealed that the experimental treatments had a significant effect $(\mathrm{p}<0.0035)$ on TPH concentration $(\mathrm{mg} / \mathrm{kg})$. Tukeys multiple correlation test $(\alpha=0.05)$ revealed three different groups (control and biostimulated treatments were significantly different), but no significant difference was observed between bioaugmented and BioauT-BiostT treatments. Fluctuations were observed between desorption and pollutant removal. The control treatment exhibited similar behavior to BiostT: both showed similar fluctuations, but this treatment had the lowest removal efficiency (13.5\%) whereas BioauT-BiostT produced 33.7\% TPH removal. BioauT had the best pollutant removal efficiency of $40.6 \%$; in addition, Pearsons correlation test indicated that the surface tension decrease $(\mathrm{mN} / \mathrm{m})$ was negatively correlated with TPH concentration $(\mathrm{mg} / \mathrm{kg})$ $(\mathrm{R}=-0.54, \mathrm{p}<0.0194)$. Figure 5 shows only the results of TPH removal (\%) and rhamnolipid production $(\mathrm{mg} / \mathrm{kg})$ obtained for BioauT-BiostT with irradiated soil (Figure 5A) and non-irradiated soil (Figure 5B). In this figure it is possible to discern that, when the quantity of rhamnolipid increases, TPH removal also increases. Although the rhamnolipid production was similar, the TPH removal (\%) was different in the two experimental treatments; perhaps this was due to the higher microbial population in non-irradiated soil and the possibility that some of these microorganisms use as an accessible carbon source the rhamnolipids produced by other microorganisms.

\section{Surface tension}

To monitor the presence of biosurfactants in the experimental treatments, the surface tension was assessed in extracts of all analyzed soil samples. An extraction solution with a surface tension of $75.2 \mathrm{mN} / \mathrm{m}$ was used, and this was considered to be the initial surface tension in all experimental units. In the experimental treatments with irradiated soil (Table 4), the greatest surface tension decrease (taken as the difference between the initial and the final surface tensions) was observed in BioauT-BiostT $(19.6 \mathrm{mN} / \mathrm{m})$ on day 10 , and a similar result was observed in Biost $(18 \mathrm{mN} / \mathrm{m})$ on the same day. In the non-irradiated soil, the greatest surface tension decrease $(11.7 \mathrm{mN} / \mathrm{m})$ was observed in BiostT
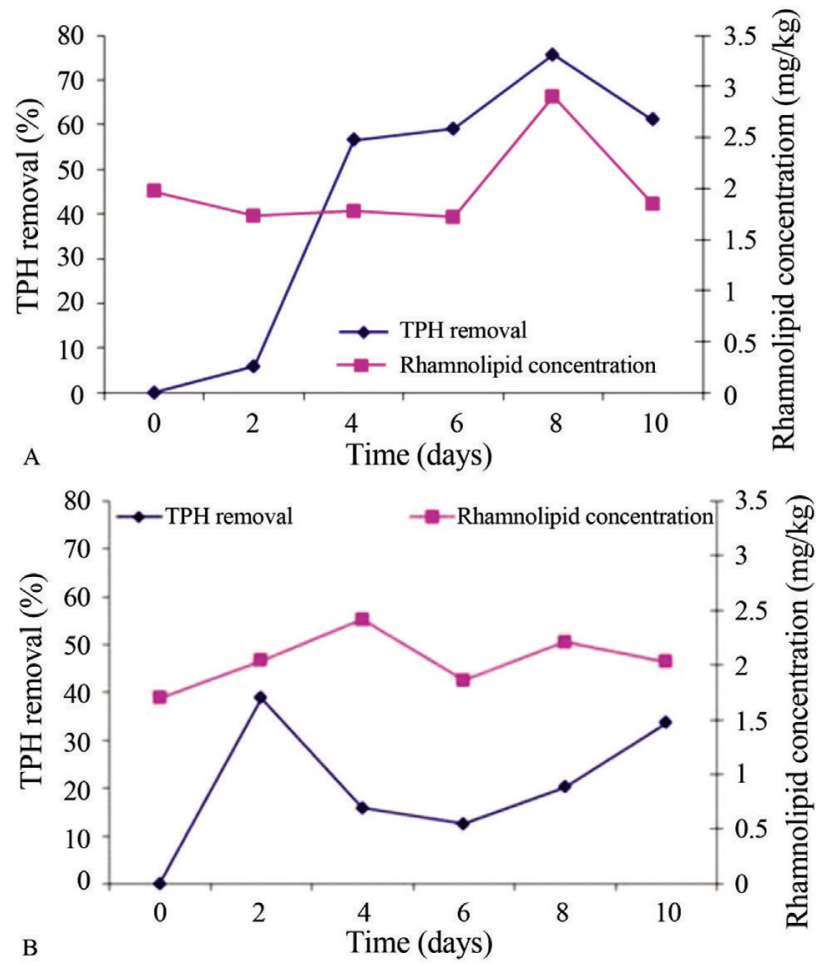

Figure 5 - Rhamnolipid concentration vs. TPH removal from BioauTBiostT in A) irradiated soil and B) non-irradiated soil.

at day 10 , and the second best result was $10 \mathrm{mN} / \mathrm{m}$ in BioauT. Consequently, microbial populations with and without irradiation could produce surface active substances that promote changes in the surface tension as P. putida does.

\section{Rhamnolipid content}

Rhamnolipids were present in all treatments with irradiated and non-irradiated soil (Table 4). In the irradiated soil, again, the best treatment was BioauT-BiostT; it had the highest rhamnolipid content with a maximum of $2.9 \mathrm{mg} / \mathrm{kg}$ at day 8 . This was followed by the control and bioaugmented treatments with $2.05 \mathrm{mg} / \mathrm{kg}$ at day 4 ; under the latter conditions, rhamnolipid production was positively correlated with $[\mathrm{N}](\mathrm{R}=0.69, \mathrm{p}<0.0031)$ and negatively correlated with $\mathrm{BacG}(\mathrm{R}=-0.64, \mathrm{p}<0.0094)$. The lowest production of rhamnolipids was obtained with BiostT $(1.46 \mathrm{mg} / \mathrm{kg})$ at day 6 and, under these conditions, a correlation was observed between $\mathrm{BacG}$ and rhamnolipid concentration $(\mathrm{R}=-0.62, \mathrm{p}<0.0168)$.

In the non-irradiated soil, rhamnolipid production was $1.79 \mathrm{mg} / \mathrm{kg}$ in the control on the second day and, with biostimulation, it was $1.33 \mathrm{mg} / \mathrm{kg}$ on the last experimental day, which was the lowest level of rhamnolipid production. The results with BiostT were similar to the results obtained with the control treatment. BioauT-BiostT yielded the best result with $2.42 \mathrm{mg} / \mathrm{kg}$ rhamnolipids at day 4 . In general, lower rhamnolipid production was observed with non-irra- 
Table 4 - Indicators of biosurfactant production in the experimental treatments.

\begin{tabular}{|c|c|c|c|c|c|c|c|c|}
\hline \multirow[t]{3}{*}{ Time (days) } & \multicolumn{8}{|c|}{ Rhamnolipid concentration $(\mathrm{mg} / \mathrm{kg})$} \\
\hline & \multicolumn{2}{|c|}{ Control } & \multicolumn{2}{|c|}{ Biostimulated } & \multicolumn{2}{|c|}{ Bioaugmented } & \multicolumn{2}{|c|}{ Bioau-Biost } \\
\hline & IS & NIS & IS & NIS & IS & NIS & IS & NIS \\
\hline 0 & $1.83 \pm 0.07$ & $1.79 \pm 0.09$ & $1.88 \pm 0.06$ & $1.6 \pm 0.18$ & $2.25 \pm 0.21$ & $1.70 \pm 0.03$ & $1.97 \pm 0.24$ & $1.70 \pm 0.35$ \\
\hline 2 & $1.98 \pm 0.19$ & $1.79 \pm 0.09$ & $1.73 \pm 0.18$ & $1.97 \pm 0.19$ & $1.82 \pm 0.14$ & $1.69 \pm 0.03$ & $1.73 \pm 0.20$ & $2.04 \pm 0.13$ \\
\hline 4 & $2.05 \pm 0.05$ & $1.73 \pm 0.08$ & $1.70 \pm 0.04$ & $1.50 \pm 0.32$ & $2.05 \pm 0.12$ & $1.69 \pm 0.03$ & $1.78 \pm 0.25$ & $2.42 \pm 0.18$ \\
\hline 6 & $1.66 \pm 0.05$ & $1.74 \pm 0.07$ & $1.46 \pm 0.28$ & $1.71 \pm 0.20$ & $1.65 \pm 0.00$ & $1.61 \pm 0.03$ & $1.72 \pm 0.22$ & $1.86 \pm 0.44$ \\
\hline 8 & $1.75 \pm 0.14$ & $1.59 \pm 0.01$ & $1.54 \pm 0.16$ & $1.41 \pm 0.07$ & $1.90 \pm 0.02$ & $1.54 \pm 0.05$ & $2.90 \pm 0.03$ & $2.21 \pm 0.16$ \\
\hline \multirow[t]{2}{*}{10} & $1.70 \pm 0.14$ & $1.61 \pm 0.06$ & $1.59 \pm 0.19$ & $1.33 \pm 0.17$ & $1.79 \pm 0.15$ & $1.54 \pm 0.05$ & $1.85 \pm .08$ & $2.03 \pm 0.19$ \\
\hline & \multicolumn{8}{|c|}{ Final surface tension $(\mathrm{mN} / \mathrm{m})$} \\
\hline 0 & $65.3 \pm 0.37$ & $65.9 \pm 0.44$ & $63.1 \pm 0.30$ & $67.0 \pm 0.28$ & $64.2 \pm 0.61$ & $67.6 \pm 0.25$ & $56.9 \pm 0.85$ & $67.4 \pm 0.44$ \\
\hline 2 & $65.6 \pm 0.69$ & $67.9 \pm 0.61$ & $58.7 \pm 0.70$ & $66.0 \pm 0.35$ & $66.0 \pm 0.51$ & $67.7 \pm 0.23$ & $63.9 \pm 0.98$ & $66.8 \pm 0.49$ \\
\hline 4 & $60.0 \pm 0.92$ & $66.2 \pm 0.32$ & $61.6 \pm 0.51$ & $66.4 \pm 0.50$ & $65.9 \pm 0.49$ & $67.3 \pm 0.32$ & $63.5 \pm 0.65$ & $66.5 \pm 0.16$ \\
\hline 6 & $63.8 \pm 1.08$ & $68.8 \pm 0.49$ & $64.2 \pm 0.81$ & $67.7 \pm 0.68$ & $62.9 \pm 2.71$ & $67.3 \pm 0.86$ & $62.2 \pm 1.09$ & $67.5 \pm 0.56$ \\
\hline 8 & $64.6 \pm 0.55$ & $67.6 \pm 0.61$ & $64.5 \pm 0.51$ & $67.4 \pm 0.65$ & $62.2 \pm 0.96$ & $65.5 \pm 0.44$ & $64.8 \pm 1.16$ & $67.5 \pm 0.47$ \\
\hline 10 & $63.5 \pm 1.07$ & $67.6 \pm 0.64$ & $57.2 \pm 1.57$ & $63.5 \pm 0.58$ & $65.6 \pm 0.68$ & $64.5 \pm 0.28$ & $55.6 \pm 0.60$ & $67.3 \pm 0.58$ \\
\hline
\end{tabular}

Initial surface tension $=75.2 \mathrm{mN} / \mathrm{m}$; IS $=$ Irradiated soil; NIS $=$ Non-irradiated soil $\pm \pm=$ Standard deviation

diated soil than with irradiated soil. In the biostimulated and Bioau-Biost treatments the rhamnolipid concentration was correlated with BacG $(\mathrm{R}=0.50, \mathrm{p}<0.0548$ and $\mathrm{R}=-0.67, \mathrm{p}<0.0043$, respectively). The rhamnolipid production observed in this work could be attributed to BacG.

\section{Discussion}

The type of soil used in this work is characterized by aged pollutants with relatively high organic matter levels and a clay-like texture that could limit the biodegradation of the petroleum pollutants therein (Gardner and Klute, 1982). In these experiments, the $\mathrm{pH}$ ranges favored bacterial growth and ensured the establishment of $P$. putida in the soil ( $\mathrm{pH}$ adjustments were not necessary). Humidity remained constant and indicated that the temperature employed was adequate.

Gamma irradiation applied to the soil destroyed some and inactivated temporarily others of the native microorganisms; it could be inferred that the latter kinds of microbes produce endospores that make them very resistant to irradiation. Therefore, the irradiated soil had very different strains as well as quantities of microorganisms compared with the non-irradiated soil (naturally contaminated soil).

In spite of the nutrient consumption in the biostimulated soil, the cumulative $\mathrm{CO}_{2}$ evolution in this experiment was lower than that in the control treatment. Regardless, the nutrient ratio used in the current study (100:10:1, C:N:P) was sufficient to activate the autochthonous soil microorganisms and induce them to produce rhamnolipids. Our results are similar to those of other authors (Haddox, 1997; Liebeg and Cutright, 1999; Ruberto et al., 2003) who did not observe significant microbial growth in their BiostT, even though $\mathrm{N}$ and $\mathrm{P}$ were added to the soil at concentrations found in healthy soils. In this work, $\mathrm{P}$ was more rapidly depleted than $\mathrm{N}$ in the biostimulated and Bioau-Biost experimental treatments, but $\mathrm{N}$ was more important for biosurfactant production than P. A possible explanation for this could be that $\mathrm{P}$ was initially less available to the microorganisms in the soil (Silvia et al., 1999); thus, when it was added in solution to the soil, the microorganisms demonstrated a preference for this nutrient over the others. Total $\mathrm{N}$ did not show relevant changes in concentration in any of the experimental treatments. However, our results showed that, in the bioaugmented treatments with non-irradiated soil, $\mathrm{N}$ stimulated fungal growth and, in irradiated soil, this nutrient stimulated BacG and also favored rhamnolipid production.

The relative abundance of $P$. putida in the bioaugmented and Bioau-Biost experimental treatments and the cumulative $\mathrm{CO}_{2}$ evolution revealed that $P$. putida was not inhibited by either the autochthonous microorganisms or the nutrients added (the added $\mathrm{C}: \mathrm{N}: \mathrm{P}$ ratio was adequate for $P$. putida growth). A possible explanation for this result is that the inoculum still contained low concentrations of macro- ( $\mathrm{N}$ and $\mathrm{P}$ ) and micronutrients, as well as glucose, which allowed the establishment of the microorganisms in the soil. Moreover, P. putida has advantages over other bacteria because it does not require an adaptation time (before or after soil inoculation) as do Pseudomonas spp. and Acinetobacter strain B-2-2 (Haddox, 1997; Ruberto et al., 2003). The fungal colony counts (maximum cell growth at day 6) and the cumulative $\mathrm{CO}_{2}$ evolution in the BioauT with irradiated and non-irradiated soil, as well as the corre- 
lation observed between fungal and bacterial growth, suggest that fungal growth was favored by the presence of $P$. putida (maximum cell growth at day 6), and that they could work synergistically; this finding agrees with findings in other studies (Bouchez et al., 1995; Aitken et al., 1998; Chávez-Gómez et al., 2003).

As the highest TPH removal was obtained in the experimental treatments with $P$. putida, these results confirm that the autochthonous microorganisms were incapable of pollutant removal (as can be seen in the results for the non-irradiated soils, control and BiosT), or alternatively that the nutrients did not increase the potential of the autochthonous degrading microorganisms, and this coincides with other reports (Nyman, 1999; Ruberto et al., 2003). These findings can be attributed to the different responses of each microorganism to the types and amounts of available nutrients. As in other reports (Trzesicka-Mlynarz and Ward, 1996; Madsen and Kristensen, 1997), in our experiments improvements in pollutant removal were only obtained in the presence of external inocula.

The surface tension changes in the soil extracts confirmed the presence of biosurfactants. The fluctuations in the surface tension changes and in the rhamnolipid concentrations could be due to a larger number of microorganisms that were reactivated in the non-irradiated soil consuming biosurfactants as co-substrates (Volkering et al., 1998). Moreover, the pollutant desorption observed during these experiments could be attributed to the biosurfactants (including rhamnolipids) produced by the microorganisms or to the disruption of cellular remnants in the soil, as in the report of Schippers et al. (2005). In other reports (Mackay and Gschwend, 2001; Hwang and Cutright, 2002), a similar phenomenon has been observed and was attributed mainly to cellular disruption in dissolved organic matter or in acid-soluble humic acids. Besides, similar surface tension decreases have been reported (Johnsen and Karlson, 2004), but in liquid culture with different microorganisms using polycyclic aromatic hydrocarbons as the carbon source. It has been suggested (Jordan et al., 1999) that biosurfactant production in soils is due to the need to make the nutrients available, and a characteristic of these soils is their low nutrient availability (mainly $\mathrm{N}, \mathrm{C}$, and $\mathrm{P}$ ) due to the presence of pollutants. It can be inferred that biosurfactant production by microorganisms under these conditions is due to the same process of making the nutrients available and uses certain TPH as carbon sources. In the irradiated soil, the surface tension was smaller than in the non-irradiated soil. Nevertheless, it was possible to observe a correlation between the TPH concentration and surface tension in the bioaugmented non-irradiated soil.

The presence of microorganisms highly resistant to gamma irradiation can be inferred, as well as that of rhamnolipid producers; hence, it is likely that $P$. putida and/or Pseudomonas spp. were present in the polluted soil as autochthonous microorganisms. The main achievement of our work is that we have shown P. putida can adapt to this type of soil and remove pollutants through its rhamnolipid production; the rates of TPH removal were similar to those reported for other microorganisms (Ross et al., 1995; Rhaman et al., 2002b) but in our work they were enhanced within a short time. This study demonstrated that $P$. putida (a non-pathogenic microorganism) is able to improve the removal of TPH from soil through its in situ rhamnolipid production.

\section{Conclusion}

The highest TPH removal was obtained in BioauTBiostT with irradiated soil (modified microbial population), this treatment had the highest rhamnolipid production $(2.90 \mathrm{mg} / \mathrm{kg}$, at day 8$)$; these low lipid concentrations together with nutrients and inoculated bacteria were effective in enhancing pollutant removal, which reached $75.6 \%$ at day 8 . Besides it can be observed that $\mathrm{N}$ had a greater effect on biosurfactant production in the soil than P. Moreover, with non-irradiated soil (with native microorganisms), the rhamnolipid production was $2.42 \mathrm{mg} / \mathrm{kg}$ at day 4 but TPH removal was only $15.9 \%$. Despite the similar amounts of rhamnolipid produced, $P$. putida was not able to remove $\mathrm{TPH}$ at the same rate; this could be attributed to the different types of strains that could grow with $P$. putida. Also $P$. putida (BiaugT) could enhance the TPH removal in the non-irradiated soil. The methodology employed in this work allowed us to determine the behavior of $P$. putida in aged polluted soil and their effectiveness in biosurfactant production and TPH removal. The results show this could be an attractive approach in field-scale bioremediation.

\section{Acknowledgments}

We would like to thank the ININ-gamma irradiation department for the gamma irradiation of the soil and Adriana Verdejo (UNAM-School of Chemistry) for assistance in tensiometer determinations. We are grateful to CONACYT for the support to complete this research.

\section{References}

Aitken M, Stringfellow WT, Nagel R, Kazunga CH, Chen S (1998) Characteristic of phenanthrene-degrading bacteria isolated from soils contaminated with polycyclic aromatic hydrocarbons. Can J Microbiol 44:743-752.

Amézcua-Allieri MA, Lead JR, Meléndez-Estrada J, RodríguezVázquez R (2003) Phenanthrene removal in selected mexican soils by the fungus Penicillium frequentans: Role of C:N ratio and water content. Soil Sediment Contam 12:387-399.

Amézcua-Vega C, Ferrera-Cerrato R, Esparza García F, RíosLeal E, Rodríguez-Vázquez R (2004) Effect of combined nutrients on biosurfactants produced by Pseudomonas putida. J Environ Sci Heal A 39:2983-2991.

Arce-Ortega JM, Rodríguez-Vázquez R, Rojas-Avelizapa NG (2004) Identification of recalcitrant hydrocarbons present in 
drilling waste polluted soil. J Environ Sci Heal A 39:15351545 .

Banks MK, Govindaraju RS, Schwab AP, Kulakow R, Finn J (2000) Phytoremediation of Hydrocarbon-Contaminated Soil. Lewis Publishers, CRC press LLC, USA.

Bouchez M, Blanchet D, Vandecasteele JP (1995) Degradation of polycyclic aromatic hydrocarbons by pure strains and by defined strain associations: Inhibition phenomena and cometabolism. Appl Microbiol Biotechnol 43:156-164.

Chávez-Gómez B, Quintero R, Esparza-García F, Mesta-Howard AM, de la Serna FJZD, Hernández-Rodríguez $\mathrm{CH}$, Guillén T, Poggi-Varaldo HM, Barrera-Cortes J, Rodríguez-Vázquez R (2003) Removal of phenanthrene from soil by bacterial co-cultures of bacteria and fungi pregrown on sugarcane bagasse pith. Bioresource Technol 89:177-183.

Clark EF (1982) Agar-plate methods for total microbial count. In: Page AL et al. (eds) Methods of Soil Analysis. American Society of Agronomy, Madison, pp 1460-1466.

Cline M (1994) Principles of soil sampling. Soil Sci 58:275-288.

Cookson JT (1995) Bioremediation engineering: Design and application. Mc. Graw Hill, New York, pp 205-258.

Diario Oficial de la Federación (DOF) (2005) NOM-138SEMARNAT/SS-2003, Norma Oficial Mexicana, Límites máximos permisibles en hidrocarburos en suelos y las especificaciones para su caracterización y remediación. [Official Mexican Standard, Maximal permissible limits for hydrocarbons in soils and specifications for their characterization and remediation] Mexico.

Fox S, Bala GA (2000) Production of surfactant from Bacillus subtillis ATCC 21332 using potato substrates. Bioresource Technol 75:235-240.

Gardner HW, Klute A (1982) Total water content and water capacity. In: Page AL et al. (eds) Methods of Soil Analysis. American Society of Agronomy, Madison, pp 1460-1466.

Haddox DC, Sauer NE, Cutright TJ (1997) Preliminary respirometer studies for bioremediation of PAH contaminated soils. In: Wise DL (ed) Global Environmental Biotechnology. Kluwer Academic Publishers, USA, pp 355-36.

Hwang S, Cutright TJ (2002) Biodegradability of aged pyrene and phenanthrene in a natural soil. Chemosphere 47:891-899.

Instituto Nacional de Estadística, Geografía e Informática (1997) Estadísticas del Medio Ambiente, México, 1997: Informe de la Situación General en Materia de Equilibrio Ecológico y Protección al Ambiente, 1995-1996. INE-SEMARNAT, Mexico, pp 28-56.

Instituto Nacional de Investigaciones Nucleares (ININ) (2010) Planta de Irradiación gamma. Available at http://www.inin.gob.mx/ Accessed 10 august 2010.

Johnsen AR, Karlson U (2004) Evaluation of bacterial strategies to promote the bioavailability of polycyclic aromatic hydrocarbons. Appl Microbiol Biot 63:452-459.

Jordan RN, Nichols EP, Cunningham AB (1999) The role of (bio) surfactant sorption in promoting the bioavailability of nutrients localized at the solid-water interface. Wa Sci Technol 39:91-98.

Liebeg EW, Cutright TJ (1999) The investigation of enhanced bioremediation through the addition of macro and micro nutrients in a PAH contaminated soil. Int Biodeter Biodegr 44:55-64
Mackay AA, Gschwend PM (2001) Enhanced concentration of PHAs in groundwater at a coal tar site. Environ Sci Technol 35:1320-1328.

Madsen T, Kristensen P (1997) Effects of bacterial inoculation and nonionic surfactants on degradation of polycyclic aromatic hydrocarbons in soil. Environ Toxicol Chem 16:631637.

Maier RM, Soberón-Chávez G (2000) Pseudomonas aeruginosa rhamnolipids: Biosynthesis and potential applications. Appl Microbiol Biotechnol 54:625-633.

Martínez-Toledo A, Ríos-Leal E, Vázquez-Duhalt R, GonzálezChávez M del C, Esparza-García JF, Rodríguez-Vázquez R (2006) Role of phenanthrene in rhamnolipid production by P. putida in different media. Environ Technol 27:137-142.

Martínez-Toledo A, Rodríguez-Vázquez R (2011) Response surface methodology (Box-Behnken) to improve a liquid media formulation to produce biosurfactant and phenanthrene removal by Pseudomonas putida. Ann Microbiol doi: 10.1007/s13213-010-0179-0.3:605-613.

Muñoz-Iniestra DJ, Mendoza-Cantú A, López-Galindo F, SolerAburto A, Hernández-Moreno MM (2000) Manual de Métodos de Análisis de Suelos. UNAM, Mexico.

Noordman WH, Ji W, Brusseu, ML, Janssen, DB (1998) Effects of rhamnolipid biosurfactants on removal of phenanthrene from soil. Environ Sci Technol 32:1802-1812.

Nyman JA (1999) Effects of the crude oil and chemical additives on metabolic activity of mixed microbial populations in fresh marsh soils. Microbial Ecol 37:152-162.

Rhaman KSM, Thahira-Rhaman J, McClean S, Marchan R, Banat IM (2002a) Rhamnolipids biosurfactants productions by strains of Pseudomonas aeruginosa using low cost raw materials. Biotechnol Progr 18:1277-1281.

Rhaman KSM, Banat IM, Thahira J, Thayumanavan Tha, Lakshmanaperumalsamy P (2002b) Bioremediation of gasoline contaminated soil by bacterial consortium amended with poultry litter, coir pith and rhamnolipid biosurfactant. Bioresource Technol 81:25-32.

Riser-Roberts E (1998) Remediation of Petroleum of Contaminated Soils: Biological, Physical and Chemical Processes. Lewis Publisher, Washington D.C. 54 pp.

Roldán-Martín A, Esparza-García F, Calva-Calva G, RodríguezVázquez R (2006) Effects of mixing low amounts of orange peel (Citrus reticulata) with hydrocarbon-contaminated soil in solid culture to promote remediation. J Environ Sci Heal A 41:1-13.

Ross B, Marien Z, Senior E (1995) Bioremediation of an oil contaminated soil by fungal intervention. In: Battelle Memorial Int. Bioaugmentation for Site Remediation 3. In Situ and On Site Bioremediation. Symposium, San Diego, California 4, pp 24-27.

Ruberto L, Vázquez SC, Mac Cormack WP (2003) Effectiveness of the natural bacterial flora, biostimulation and bioaugmentation on the bioremediation of a hydrocarbon contaminated Antarctic soil. Int Biodeter Biodegr 52:115-125.

Schippers C, Gener K, Muller T, Scheper T (2000) Microbial degradation of phenanthrene by addition of a sophorolipid mixture. J Biotechnol 83:189-198.

Schwab AP, Su J, Wetzel S, Pekarek S, Banks MK (1999) Extraction of petroleum hydrocarbons from soil by mechanical shaking. Environ Sci Technol 33:1940-1945. 
Secretaría del medio ambiente y recursos naturales. SEMARNAT (2008) Informe 2008. Informe de la situación del medio ambiente en México. Compendio de estadísticas ambientales. Available at http//app1.semarnat.gob.mx/dgeia/ informe_2008/07_residuos/cap_6.html. Accessed 5 September 2009.

Silvia MD, Fuhrmann JJ, Hartel, PG, Zuberer DA (1999) Principles and Applications of Soil Microbiology. Prentice Hall, New Jersey, Chap 16.

Trzesicka-Mlynarz D, Ward OP (1996) Degradation of fluoranthene in a soil matrix by indigenous and introduced bacteria. Biotechnol Lett 18:181-186.

US Environmental protection Agency (USEPA) SW 846 Method 8440 Recoverable Petroleum Hydrocarbons by Infrared
Spectrophotometryc, Test Methods for Evaluating Solid Waste, Physical/Chemical Methods SW 846, $3^{\text {rd }}$ Ed. Available at http://www.epa.gov/epaoswer/hazwaste/test/main. htlm. Accessed 12 February 2006.

Volkering F, Breure AM, Rulkens WH (1998) Microbiological aspects of biosurfactant use for biological soil remediation. Biodegradation 8:401-417.

Volkering F, Breure AM, Van Andel JG, Rulkens WH (1995) Influence of nonionic surfactant on bioavailability and biodegradation of polycyclic aromatic hydrocarbons. Appl Environ Microbiol 61:1699-1705.

All the content of the journal, except where otherwise noted, is licensed under a Creative Commons License CC BY-NC. 